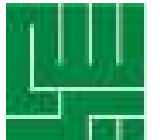

\title{
Pemeriksaan Anal Swab Berulang untuk Meningkatkan Keakuratan Diagnosis Oxyuris vermicularis pada Anak-anak Di Kelurahan Tanah Tinggi, Johar Baru
}

\section{Examination of Repeated Anal Swabs to Improve the Accuracy of Diagnosis of Oxyuris vermicularis in Children in Kelurahan Tanah Tinggi, Johar Baru}

\author{
Rika Ferlianti, Elita Donanti, Ambar Hardjanis. \\ Department of Parasitology, Faculty of Medicine, Universitas YARSI, \\ Jakarta
}

KATA KUNCI KEYWORDS

ABSTRAK diagnosis, oxyuriasis, anal swab, anak-anak diagnosis, oxyuriasis, anal swab, children

Oxyuriasis adalah penyakit infeksi yang disebabkan oleh Oxyuriasis vermicularis atau Enterobius vermicularis (cacing kremi). Kelembaban udara yang tinggi, dan sanitasi yang masih kurang baik di Indonesia merupakan faktor yang dapat berperan dalam perkembangan dan transmisi dari cacing kremi. Oxyuriasis terjadi pada semua usia, tetapi usia terbanyak terjadi pada anak-anak. Penelitian dilakukan di Kelurahan Tanah Tinggi, Johar baru, Jakarta Pusat karena termasuk daerah yang padat penduduk.

Untuk mengetahui keakuratan pemeriksaan anal swab berulang (tiga hari berturut-turut) dibandingkan pemeriksaan anal swab satu kali dalam menegakkan diagnosis oxyuriasis.

Jenis Penelitian ini adalah eksperimental yang menggunakan data primer melalui pemeriksaan anal swab yang dilakukan dengan metode pita plastik perekat (cellophane tape) pada 45 anak dengan rentang usia 5-10 tahun dari 3 RW yang berbeda (RW 07, RW 08, dan RW 12) di Kelurahan Tanah Tinggi.

Dari 45 anak yang ikut penelitian (anak laki-laki 23 orang dan anak perempuan 22 orang) didapatkan 73,3\% termasuk dalam kategori usia muda/prasekolah (5-6 tahun) dan 26,7\% pada anak usia sekolah (7-10 tahun). Ada peningkatan keakuratan pada pemeriksaan anal swab berulang (tiga hari berturut-turut) dibandingkan dengan satu kali pemeriksaan. Prevalensi yang didapat adalah 4,44\% untuk metode anal swab berulang, sedangkan metode satu kali adalah 2,22\%.

Pemeriksaan anal swab berulang (tiga hari berturut-turut) lebih akurat dibandingkan pemeriksaan anal swab satu kali dalam menegakkan diagnosis oxyuriasis. 
ABSTRACT Oxyuriasis is an infectious disease caused by Oxyuriasis vermicularis or Enterobius vermicularis (pinworms). High humidity and poor sanitation in Indonesia is a contribute factor for the development and transmission of pinworms. Oxyuriasis occurs at all ages but mostly in children. Research was conducted at Kelurahan Tanah Tinggi, Johar baru, Jakarta Pusat, a densely populated area.

To determine the accuracy of repeated (three consecutive days) anal swab examinations compared to one-time anal swab examination in establishing a diagnosis of oxyuriasis.

This is an experimental research using primary data collected from anal swab examinations using adhesive plastic tape (cellophane tape) in 45 children (age 5-10 years old) from 3 different $R W(R W 07,08$, and 12 in Kelurahan Tanah Tinggi). Fourty five children were recruited in this study (23 male, 22 female). $73.3 \%$ was categorized as children aged young/preschool (5-6 years old) and $26.7 \%$ was children with age range 7-10 years old. There was an increase in the accuracy of the repeated (three consecutive days) anal swab compared to the one-time. The prevalence was $4.44 \%$ for the repeated method versus $2.22 \%$ for the one-time method.

Repeated anal swab examination (three consecutive days) is more accurate than one-time anal swab examination in establishing a diagnosis of oxyuriasis.

Penyakit kecacingan masih merupakan salah satu masalah kesehatan masyarakat di Indonesia. Oxyuriasis (Enterobiasis) atau cacing kremi) merupakan salah satu penyakit cacing yang sampai saat ini masih merupakan masalah bagi kesehatan. Oxyuriasis disebabkan oleh Oxyuris vermicularis (Enterobius vermicularis) merupakan cacing usus golongan nonSTH (non-Soil Transmitted Helminth) yang dapat berpindah dari satu individu ke individu yang lain tanpa perlu transmisi melalui tanah. Prevalensi oxyuriasis di dunia masih tergolong tinggi baik di negara berkembang maupun negara maju (Gillespie et al., 2001; Muller R 2002; Abidin 2009).
Di Indonesia prevalensi oxyuriasis cukup tinggi, hal ini disebabkan Indonesia merupakan negara dengan iklim tropis, kelembaban udara yang tinggi, dan sanitasi yang masih kurang baik, sehingga sesuai untuk perkembangan cacing kremi. Di Semarang, didapatkan prevalensi oxyuriasis pada anak-anak di Taman Kanak-kanak (TK) kelurahan Bulu Lor relatif tinggi yaitu sebesar 51,9\% (Suvonalya 1998). Penelitian lain juga melaporkan bahwa beberapa daerah di Jawa Tengah masih memiliki angka prevalensi oxyuriasis yang cukup tinggi yaitu sekitar 58,93\% hingga 74,31\%. (Dana 2005).

\footnotetext{
Correspondence:

Rika Ferlianti, Department of Parasitology, Faculty of Medicine, Universitas YARSI, jakarta

Email: rika.ferlianti@yarsi.ac.id
} 
Penularan infeksi cacing kremi sangat mudah terjadi pada kelompok orang yang hidup dalam satu lingkungan yang sama seperti asrama, panti asuhan, atau sekolah. Telur cacing dapat diisolasi dari debu ruangan dan menjadi sumber infeksi. Selain itu, reinfeksi mudah sekali terjadi jika tidak dilakukan pencegahan yang tepat. (Abidin 2009). Infeksi cacing kremi dapat diduga pada anak yang menunjukkan rasa gatal di sekitar anus pada waktu malam hari. Diagnosis dibuat dengan menemukan telur dan cacing dewasa. Pemeriksaan tinja untuk mendiagnosis penyakit ini kurang baik karena hasil positif kurang lebih hanya 5\% (Rusmartini 2009). Telur cacing dapat diambil dengan mudah dengan menggunakan alat anal swab yang ditempelkan di sekitar anus pada waktu pagi hari sebelum anak buang air besar dan mencuci pantat (cebok). Sebaiknya pemeriksaan ini dilakukan tiga hari berturut-turut (Abidin 2009). Pemeriksaan anal swab perlu dilakukan berulang-ulang dalam beberapa hari berturut-turut karena migrasi cacing betina yang hamil tidak teratur. Sekali pemeriksaan hanya menemukan lebih kurang 50\% dari semua infeksi, tiga kali pemeriksaan menemukan lebih kurang 90\%. Dikatakan seseorang bebas dari infeksi cacing ini jika pada pemeriksaan yang dilakukan 7 hari berturut-turut hasilnya negatif (Rusmartini 2009).

\section{METODE}

Penelitian ini sudah mendapatkan keterangan lolos kelayakan Etik Penelitian dengan No. 314/KEPUY/BIA/XI/2018 dari Lembaga Penelitian Universitas YARSI. Jenis penelitian adalah eksperimental. Sampel pada penelitian ini didapatkan dari 45 anak yang berusia 5-10 tahun di
Rw 007, 008 dan 012 Kelurahan Tanah Tinggi, Johar Baru, Jakarta Pusat. Data pada penelitian ini adalah data primer yang diperoleh dengan cara pengumpulan data menggunakan pemeriksaan anal swab yang dilakukan dengan metode pita plastik perekat (cellophane tape), yang dilakukan selama 3(tiga) hari bertutut-turut pada waktu pagi hari sebelum anak buang air besar dan mencuci bokong. Sampel yang didapatkan diperiksa dengan menggunakan pemeriksaan mikroskopik sebagai gold standar dari diagnosis oxyuriasis.

\section{HASIL}

Satu hari sebelum penelitian dilakukan penyuluhan tentang penyakit oxyuriasis di RPTRA Pulo Gundul, Johar baru. Dan dilanjutkan dengan pemberian pembekalan tatacara pemeriksaan anal swab kepada orangtua yang bersedia anaknya untuk ikut penelitian.

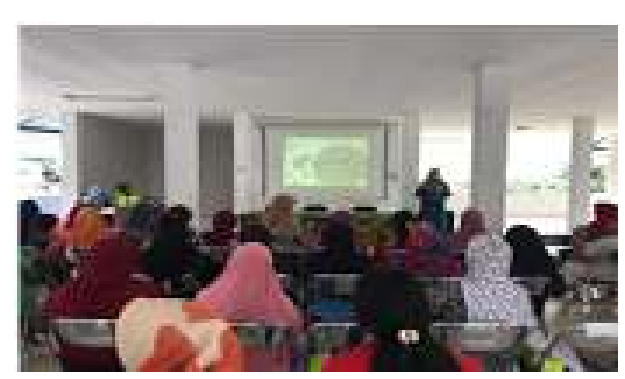

Gambar 1. Penyuluhan dan pembekalan kepada orang tua tentang oxyuriasis

\section{Karakteristik sampel}

Tempat wilayah penelitian dilakukan di tiga Rw yaitu Rw 012, Rw 08 dan Rw 07, yang dapat dilihat di tabel 1. 
Tabel 1. Distribusi Jumlah Anak Berdasarkan Wilayah Penelitian

\begin{tabular}{lcc}
\hline Wilayah & $\begin{array}{c}\text { Jumlah } \\
\text { Anak }\end{array}$ & $\begin{array}{c}\text { Presentase } \\
\mathbf{( \% )}\end{array}$ \\
\hline Rw 012 & 18 & 40 \\
Rw 008 & 15 & 33,3 \\
Rw 007 & 12 & 26,7 \\
Total & $\mathbf{4 5}$ & $\mathbf{1 0 0}$ \\
\hline
\end{tabular}

Penelitian ini diikuti oleh 45 anak yang berada dalam rentang usia 5-10 tahun. Jumlah usia anak yang berusia muda/ prasekolah (5-6 tahun) sebanyak 33 anak $(73,3 \%)$ dan anak usia sekolah (7-10 tahun) sebanyak 12 anak (26,7\%).

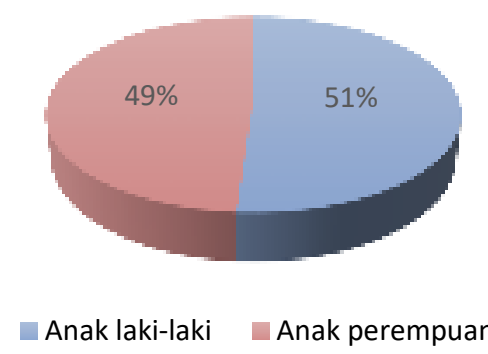

Gambar 2. Distribusi anak berdasarkan jenis kelamin di kelurahan Tanah Tinggi, Johar Baru

\section{Prevalensi Oxyuriasis}

Prevalensi oxyuriasis didapatkan dari hasil pemeriksaan anal swab selama tiga hari yang dilakukan pada 45 anak di Kelurahan Tanah Tinggi, Johar Baru, Jakarta Pusat. Hasil positif didapatkan 2 orang anak yaitu 4,44\% dan hasil negatif ada 43 orang anak yaitu 95,6\%. Hasil positif tidak didapatkan pada hari yang sama tetapi pada hari yang berbeda yaitu hari ke 1 dan hari ke 3 . Berdasarkan distribusi wilayah penelitian yang dilakukan pada $3 \mathrm{Rw}$ Kelurahan Tanah Tinggi yaitu Rw 012, Rw 08 dan Rw 07 didapatkan Rw 08 sebanyak 1 anak dan Rw 012 sebanyak 1 anak, yang dapat dilihat pada tabel 2.
Tabel 2. Distribusi Oxyuriasis berdasarkan wilayah penelitian di Kelurahan Tanah Tinggi

\begin{tabular}{lccc}
\hline \multirow{2}{*}{ Tempat } & \multicolumn{2}{c}{ Terinfeksi } & \\
& \multicolumn{2}{c}{ Oxyuriasis } & Total \\
\cline { 2 - 3 } & Iya & Tidak & \\
\hline Rw 012 & 1 & 17 & 18 \\
Rw 008 & 1 & 14 & 15 \\
Rw 007 & 0 & 12 & 12 \\
Total & $\mathbf{2}$ & $\mathbf{4 3}$ & $\mathbf{4 5}$ \\
\hline
\end{tabular}

Kemudian setiap anak digolongkan ke dalam usia muda/prasekolah dan usia sekolah untuk mengetahui distribusi usia anak terkait oxyuriasis. Didapatkan hasil positif terinfeksi oxyuriasis pada usia muda/ prasekolah adalah 1 anak $(3,03 \%)$ yaitu di usia 6 tahun sedangkan 32 anak lainnya hasilnya negatif $(96,97 \%)$. Dan hasil positif terinfeksi oxyuriasis pada usia sekolah adalah 1 anak $(8,33 \%)$ yaitu usia 9 tahun, sedangkan 11 anak lainnya hasilnya negatif $(91,67 \%)$. Untuk distribusi jenis kelamin terkait prevalensi oxyuriasis di Kelurahan Tanah Tinggi, Johar Baru dapat dilihat di tabel 3.

Tabel 3 Distribusi Jenis Kelamin dengan Prevalensi Oxyuriasis di Kelurahan Tanah Tinggi

\begin{tabular}{lcc}
\hline \multirow{2}{*}{$\begin{array}{c}\text { Jenis } \\
\text { Kelamin }\end{array}$} & \multicolumn{2}{c}{ Terinfeksi } \\
& Oxyuriasis \\
\cline { 2 - 3 } & Iya & Tidak \\
\hline Laki-laki & $2(9,1 \%)$ & $20(90,9 \%)$ \\
Perempuan & 0 & $23(100 \%)$ \\
Total & $\mathbf{2}$ & $\mathbf{4 3}$ \\
\hline
\end{tabular}

\section{PEMBAHASAN}

Penelitian yang banyak dilakukan selama ini hanya melakukan pemeriksaan anal swab satu kali untuk mendiagnosis oxyuriasis pada anakanak, sebagai contoh pada penelitian sebelumnya yaitu penelitian Hairani 
dan Annida pada tahun 2012 di Kabupaten Tanah Bambu Provinsi Kalimatan Selatan, yang mendapatkan prevalensi oxyuriasis $2,7 \%$ pada anakanak dan penelitian Chadijah dkk, tahun 2014 di Kota Palu Provinsi Sulawesi Tengah yang menunjukkan hasil perevalensinya adalah 2,22\%. Penelitian yang sekarang dilakukan merujuk kepada teori yang menyatakan bahwa pemeriksaan anal swab sekali pemeriksaan hanya menemukan lebih kurang 50\% dari semua infeksi, tiga kali pemeriksaan menemukan lebih kurang 90\% (Rusmartini 2009). Dari hasil pemeriksaan anal swab ini, jika hanya melakukan pemeriksaan anal swab sekali saja didapatkan prevalensi oxyuriasis $2,22 \%$ sedangkan jika dilakukan berulang yaitu tiga hari berturut-turut didapatkan prevalensi oxyuriasis meningkat menjadi 4,44\%. Hal ini berkaitan dengan migrasi cacing betina Oxyuris vermicularis yang hamil (gravida) tidak teratur untuk mengeluarkan telurnya ke daerah perianal (Rusmartini 2009).

Penelitian ini dilakukan di Kelurahan Tanah Tinggi, Johar Baru, Jakarta Pusat dan berdasarkan Peraturan Gubernur Provinsi Daerah Khusus Ibukota Jakarta No.90 tahun 2019 tentang "Peningkatan Kualitas Pemukiman dalam Rangka Penataan Kawasan Pemukiman Terpadu", maka penelitian ini diutamakan didaerah yang ditetapkan kumuh yaitu di Rw 012 (Kumuh berat), Rw 08 (Kumuh sedang) dan Rw 07 (Kumuh ringan). Dari hasil pemeriksaan anal swab berulang yang dilakukan sebanyak tiga hari berturutturut berdasarkan distribusi wilayah penelitian yang dilakukan pada $3 \mathrm{Rw}$ Kelurahan Tanah Tinggi yaitu Rw 012, Rw 08 dan Rw 07 didapatkan Rw 08 (kumuh sedang) sebanyak 1 anak dan
Rw 012 (kumuh berat) sebanyak 1 anak. Prevalensi oxyuriasis di daerah tersebut rendah yaitu 4,44\%, walaupun lingkungan wilayah termasuk dalam kategori kumuh. Rendahnya prevalensi ini dipengaruhi oleh banyak faktor, selain faktor lingkungan, faktor peran aktif dari Kelurahan, Puskesmas dan Para Kader dalam mensosialisasikan pengetahuan tentang PHBS (Perilaku Hidup Bersih dan Sehat) seperti mencuci tangan sebelum dan sesudah makan serta setelah buang air kepada masyarakat menyebabkan kesadaran warga akan pentingnya kesehatan meningkat (DEPKES RI 2012).

Faktor lainnya adalah pemberian obat cacing yang diminum secara rutin pada anak-anak usia sekolah yaitu 2 kali setahun di bulan Februari dan Agustus. Dengan meminum obat cacing secara teratur, dapat menghilangkan penyebab dari penyakit oxyuriasis yaitu cacing Oxyuris vermicularis. Hal ini juga terkait dengan peran aktif khususnya Puskesmas dan Para Kader di Kelurahan Tanah Tinggi, Johar Baru. Selain itu, pemberian obat cacing secara bersamaan dengan seluruh anak yang berada dalam satu lingkungan akan mencegah kemungkinan reinfeksi dan tertular dari orang yang sebelumnya sudah terinfeksi. Jika tidak ada sumber infeksi, tentu tidak akan terjadi penyakit oxyuriasis sesuai dengan konsep triad epidemiologi yaitu faktor host, agent dan environment.

Pada suatu keadaan terjadinya gangguan pada keseimbangan dinamis ini, memungkinkan agent masuk ke dalam tubuh host dan terjadilah sakit (Chandra 2009). Dari pemeriksaan anal swab yang berulang didapatkan hasil positif terinfeksi oxyuriasis yaitu pada usia muda/prasekolah adalah 1 anak yaitu 6 tahun dan pada usia sekolah 
adalah 1 anak yaitu usia 9 tahun. Dengan demikian dapat diinterpretasikan bahwa prevalensi oxyuriasis tersebar merata. Penelitian ini sejalan dengan penelitian Rosdiana (2016) didapatkan angka kejadian oxyuriasis merata di seluruh golongan usia 6-9 tahun. Prevalensi oxyuriasis yang ditemukan merata pada rentang usia berhubungan dengan aktivitas anak di taman kanak-kanak dan sekolah dasar (Cho et al., 2010). Hal ini berkaitan dengan penularan cacing kremi yang berkaitan dengan jumlah kelompok yang hidup dan beraktivitas dalam satu lingkungan yang sama seperti sekolah pada anak-anak (Abidin 2009).

\section{KESIMPULAN}

Prevelensi oxyuriasis di Kelurahan Tanah Tinggi, Johar Baru, dengan melakukan pemeriksaan anal swab berulang didapatkan hasil meningkat sebanyak dua kali dibandingkan pemeriksaan tunggal. Sehingga Pemeriksaan anal swab berulang (tiga hari berturut-turut) lebih akurat dalam menegakkan diagnosis oxyuriasis.

\section{Ucapan terima kasih}

Terima kasih kepada Hibah Internal Fakultas Kedokteran Universitas YARSI yang menjadi sumber dana untuk penelitian ini. Lurah, staff dan kader Kelurahan Tanah Tinggi, Johar Baru. Mahasiswa dan Laboran Parasitologi Kedokteran Universitas YARSI

\section{KEPUSTAKAAN}

Abidin SAN 2009. Enterobius vermucularis. Buku Ajar Parasitologi Kedokteran. Edisi 4. Jakarta: Balai Penerbit Fakultas Kedokteran Universitas FKUI.

Chadijah S, Sumolang PPF, Veridiana NN 2014. Hubungan Pengetahuan, Perilaku, dan Sanitasi Lingkungan dengan Angka Kejadian Kecacingan pada Anak Sekolah Dasar di Kota Palu. Media Litbangkes. 24(1).

Chandra B 2009. Ilmu Kedokteran Pencegahan dan Komunitas. Jakarta: Penerbit Buku Kedokteran EGC.

Cho MK, Kim DH, Son HM, Kim JY, Park MK, Kang SY et al., 2010. Parents Knowledge about Enterobiasis Might be One og the most Important Risk Factors of Enterobiasis in Children. Korean J Parasitol. 48(2): 121-6.

Dana A 2005. Hubungan tingkat pengetahuan pengasuh anak tentang kecacingan kremi dengan kejadian oxyuriasis pada anak-anak kelas 1 SD Negeri Sukorejo 3-4 Kecamatan Gunung Pati Kotamadya Semarang. Dalam Karya Tulis Ilmiah UNDIP.

Depkes RI 2012. Buku Pegangan Kader. Jakarta.

Gillespie S \& Pearson RD 2001. Principles and practice in clinical parasitology. England: John Wiley \& Sons Ltd.

Hairani B, Annida A 2012. Insidensi Parasit Pencernaan pada Anak Sekolah Dasar di Perkotaan dan Pedesaan di Kabupaten Tang Bumbu Kalimantan Selatan. Jurnal Epidemiologi dan Penyakit Bersumber Binatang. Vol 5(1)

Muller R 2002. Worms and human disease. New York: CAB International

Rosdiana E 2016. Hubungan Antara Personal Higeine dan Kejadian Infeksi Enterobiasis pada Siswa Sekolah Dasar Negeri Mojorejo 01 Bendosari Sukoharjo. Karya tulis ilmiah Universitas Muhammadiyah Surakarta

Rusmartini 2009. Parasitologi Kedokteran Ditinjau Dari Organ Tubuh Yang Diserang: Penyakit oleh Nematoda Usus. Edisi Pertama. Cetakan Pertama. Penerbit Buku Kedokteran EGC. Jakarta

Suvonalya 1998. Hubungan higiene pribadi dengan frekuensi oxyuriasis pada anak TK Bakti Pertiwi Kelurahan Bulu Lor Kotamadya Semarang. Dalam Karya Tulis Ilmiah UNDIP. 